\title{
Stimulatory effect of cobalt ions incorporated into calcium phosphate coatings on neovascularization in an in vivo intramuscular model in goats
}

Citation for published version (APA):

Birgani, Z. T., Fennema, E., Gijbels, M. J., de Boer, J., van Blitterswijk, C. A., \& Habibovic, P. (2016). Stimulatory effect of cobalt ions incorporated into calcium phosphate coatings on neovascularization in an in vivo intramuscular model in goats. Acta Biomaterialia, 36, 267-276.

https://doi.org/10.1016/j.actbio.2016.03.031

Document status and date:

Published: 01/05/2016

DOI:

10.1016/j.actbio.2016.03.031

Document Version:

Publisher's PDF, also known as Version of record

\section{Document license:}

Taverne

Please check the document version of this publication:

- A submitted manuscript is the version of the article upon submission and before peer-review. There can be important differences between the submitted version and the official published version of record.

People interested in the research are advised to contact the author for the final version of the publication, or visit the DOI to the publisher's website.

- The final author version and the galley proof are versions of the publication after peer review.

- The final published version features the final layout of the paper including the volume, issue and page numbers.

Link to publication

\footnotetext{
General rights rights.

- You may freely distribute the URL identifying the publication in the public portal. please follow below link for the End User Agreement:

www.umlib.nl/taverne-license

Take down policy

If you believe that this document breaches copyright please contact us at:

repository@maastrichtuniversity.nl

providing details and we will investigate your claim.
}

Copyright and moral rights for the publications made accessible in the public portal are retained by the authors and/or other copyright owners and it is a condition of accessing publications that users recognise and abide by the legal requirements associated with these

- Users may download and print one copy of any publication from the public portal for the purpose of private study or research.

- You may not further distribute the material or use it for any profit-making activity or commercial gain

If the publication is distributed under the terms of Article $25 \mathrm{fa}$ of the Dutch Copyright Act, indicated by the "Taverne" license above, 
Full length article

\title{
Stimulatory effect of cobalt ions incorporated into calcium phosphate coatings on neovascularization in an in vivo intramuscular model in goats
}

\author{
Zeinab Tahmasebi Birgani ${ }^{a}$, Eelco Fennema ${ }^{a}$, Marion J. Gijbels ${ }^{\text {b,c,d }}$, Jan de Boer $^{\text {a,e }}$, \\ Clemens A. van Blitterswijk ${ }^{\mathrm{a}, \mathrm{e}}$, Pamela Habibovic ${ }^{\mathrm{a}, \mathrm{e}, *}$ \\ a Department of Tissue Regeneration, MIRA Institute for Biomedical Technology and Technical Medicine, University of Twente, P.O. Box 217, 7500 AE Enschede, The Netherlands \\ ${ }^{\mathrm{b}}$ Department of Pathology, Cardiovascular Research Institute Maastricht, Maastricht University, P.O. Box 616, 6200 MD Maastricht, The Netherlands \\ ${ }^{\mathrm{c}}$ Department of Molecular Genetics, Cardiovascular Research Institute Maastricht, Maastricht University, P.0. Box 616, 6200 MD Maastricht, The Netherlands \\ ${ }^{\mathrm{d}}$ Department of Medical Biochemistry, The Academic Medical Center, Meibergdreef 9, 1105 AZ Amsterdam, The Netherlands \\ e MERLN Institute for Technology-Inspired Regenerative Medicine, Maastricht University, P.O. Box 616, 6200 MD Maastricht, The Netherlands
}

\section{A R T I C L E I N F O}

\section{Article history:}

Received 14 November 2015

Received in revised form 2 February 2016

Accepted 17 March 2016

Available online 18 March 2016

\section{Keywords:}

Calcium phosphate

Poly(lactic acid)

Cobalt

Neovascularization

In vivo

\begin{abstract}
A B S T R A C T
Rapid vascularization of bone graft substitutes upon implantation is one of the most important challenges to overcome in order to achieve successful regeneration of large, critical-size bone defects. One strategy for stimulating vascularization during the regeneration process is to create a hypoxic microenvironment by either directly lowering the local oxygen tension, or by applying hypoxia-mimicking factors. Cells compensate for the hypoxic condition by releasing angiogenic factors leading to new blood vessel formation. In the present study, we explored the potential of cobalt ions $\left(\mathrm{Co}^{2+}\right)$, known chemical mimickers of hypoxia, to stimulate vascularization within a bone graft substitute in vivo. To this end, $\mathrm{Co}^{2+}$ ions were incorporated into calcium phosphate (CaPs) coatings deposited on poly(lactic acid) (PLA) particles with their effect on the formation of new blood vessels studied upon intramuscular implantation in goats. PLA particles and CaP-coated particles without $\mathrm{Co}^{2+}$ ions served as controls. Pathological scoring of the inflammatory response following a 12 -week implantation period showed no significant differences between the four types of materials. Based on histological and immunohistochemical analyses, both blood vessel area and number of blood vessels in CaP-coated PLA particles containing $\mathrm{Co}^{2+}$ were higher than in the uncoated PLA particles and CaP-coated PLA particles without $\mathrm{Co}^{2+}$. Analysis of blood vessel size distribution indicated abundant formation of small blood vessels in all the samples, while large blood vessels were predominantly found in PLA particles coated with $\mathrm{CaP}$ containing $\mathrm{Co}^{2+}$ ions. The results of this study support the use of CaPs containing $\mathrm{Co}^{2+}$ ions to enhance vascularization in vivo.
\end{abstract}

\section{Statement of Significance}

In this work, we have investigated the potential of cobalt ions, incorporated into thin calcium phosphate ( $\mathrm{CaP}$ ) coatings that were deposited on particles of poly(lactic acid) (PLA), to induce neovascularization in vivo. Qualitative and quantitative histological and immunohistochemical analyses showed that both the number of blood vessels and the total blood vessel area were higher in CaP-coated PLA particles containing cobalt ions as compared to the uncoated PLA particles and CaP-coated PLA particles without the metallic additive. Furthermore, a wider distribution of blood vessel sizes, varying from very small to large vessels was specifically observed in samples containing cobalt ions.

This in vivo study will significantly contribute to the existing knowledge on the use of bioinorganics, which are simple and inexpensive inorganic factors that can be used to control relevant biological process during tissue regeneration, such as vascularization. As such, we are convinced that this manuscript will be of interest to the readers of Acta Biomaterialia.

(c) 2016 Acta Materialia Inc. Published by Elsevier Ltd. All rights reserved.

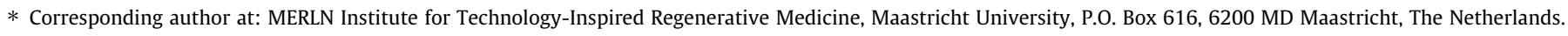
E-mail address: p.habibovic@maastrichtuniversity.nl (P. Habibovic).
} 


\section{Introduction}

Angiogenesis plays a pivotal role in skeletal development and regenerative fracture repair [1,2]. It has been previously shown that inadequate or abnormal vascularization negatively affects the bone healing process, leading to inferior bone formation, or formation of fibrous tissue in the bone defect area [2,3]. Therefore, the establishment and the maintenance of vasculature remains an important challenge in bone regenerative strategies, especially when large, critical-size bone defects are considered.

Surgical approaches such as induced membrane and distraction osteogenesis have been traditionally used as methods for increasing the vascularization of natural or synthetic bone graft substitutes. Although such techniques have shown some successes, their use is associated with important drawbacks including the need for a second surgery, pain, extended surgical procedures, and longer recovery times [4].

Bone regenerative strategies based on biomaterials and tissueengineered constructs have offered a number of interesting solutions to couple processes of angiogenesis and osteogenesis, as reviewed in detail by Mercado-Pagán et al. [4], Laschke and Menger [5], Lovett et al. [6] and Nguyen et al. [7]. A common strategy to improve vascularization in bone graft substitutes revolves around tuning the scaffold properties, such as chemical composition, porosity and mechanical strength $[4,5,8]$. Further, functionalization of scaffolds by growth- and other stimulatory factors, such as vascular endothelial growth factor (VEGF) [9-11] and fibroblast growth factor (FGF) [12], and incorporation of blood vessel forming cells such as endothelial cells and pericytes [4,13-15], are typical tissue engineering approaches to promote angiogenesis and establish the vascularization within bone graft substitutes. Complementary techniques such as mechanical [16-18] and electrical stimulation [19], and microfabrication techniques [20] have also been investigated. Alternatively, induction of angiogenesis by lowering the oxygen tension, or incorporating hypoxia-mimicking factors into the scaffold, has also been recognized as a promising approach [21]. Cells respond to hypoxia by producing higher levels of pro-angiogenic factors such as VEGF and erythropoietin (EPO), in turn forming more blood vessels in order to compensate for the low oxygen tension [22]. For example, Doorn et al. showed that a small molecule phenanthrolin, a hypoxia-mimicking factor, upregulated the expression of hypoxia-target genes in human mesenchymal stromal cells. Furthermore, the release of phenanthrolin from Matrigel plugs resulted in the induction of blood vessel formation in a mouse model [21].

Cellular responses to low oxygen tension can be mimicked by cobalt ions $\left(\mathrm{Co}^{2+}\right)$, a process sometimes referred to as chemical hypoxia $[23,24]$. Being a transition metal, $\mathrm{Co}^{2+}$ can replace $\mathrm{Fe}^{2+}$ from the catalytic sites of the Hypoxia Inducible Factor (HIF) prolyl-hydroxylases (PHDs), leading to inhibition of its enzymatic function [25]. As a result, the continuous destruction of HIF1- $\alpha$ is stopped, and HIF-responsive gene expression is upregulated [26]. $\mathrm{Co}^{2+}$ has previously been shown to induce in vitro angiogenesis in 3D scaffolds [27], as well as promote in vivo neovascularization in bone tissue-engineered constructs [28,29].

Calcium phosphates (CaPs) are the most widely used family of biomaterials in the field of bone regeneration, owing to their chemical resemblance to the mineral portion of bone [30]. CaP ceramics are, however, intrinsically brittle, which is why they are often combined with other materials, like polymers, which are more versatile in terms of mechanical properties [31,32]. CaPs and CaP-based hybrid systems are biocompatible, osteoconductive and, in some cases, even osteoinductive [33,34], having the added advantage of being relatively inexpensive and available in large quantities. However, they are still not considered a full alternative to the golden standard for bone regeneration, being autograft [35]. One of the promising methods to improve the bioactivity of CaPs, while retaining their synthetic character, is the use bioinorganics [36] such as magnesium, zinc and strontium. Many of these elements are present in bone mineral, often in trace amounts, and are known for their role in the bone formation and remodeling processes [36-38]. Some studies have also explored the possibility of incorporating $\mathrm{Co}^{2+}$ into CaPs to investigate their effect in vitro $[39,40]$.

In an attempt to develop bone graft substitutes that stimulate angiogenesis, in this study we have deposited CaP coatings with or without $\mathrm{Co}^{2+}$ on particles of poly(lactic acid) (PLA), a widely used aliphatic polyester in biomedical applications [41], by employing a previously described biomimetic method [39,42]. The constructs were implanted intramuscularly in 9 goats, and the formation of new blood vessels was assessed using histological and immunohistochemical techniques.

\section{Materials and methods}

\subsection{Material production}

CaP-coated poly(D,L-lactic acid) (PLA) particles with and without $\mathrm{Co}^{2+}$ incorporation in the $\mathrm{CaP}$ phase were used in this study. Uncoated PLA particles served as a control.

A low molecular weight PLA (Purasorb PDL05, Purac, MW: $59,000 \mathrm{~g} / \mathrm{mole}$ ) was used to produce polymeric particles by means of extrusion as described previously [43]. In short, PLA was extruded using a twin-screw extruder with conical nonconverging screws (Artecs BV, Enschede, the Netherlands) at $150{ }^{\circ} \mathrm{C}$ with a screw rotation speed of $100 \mathrm{rpm}$. After $5 \mathrm{~min}$, the rod-shaped polymer was allowed to flow out of the extruder. The rods were ground and sieved to obtain particle sizes within the range $0.5-1 \mathrm{~mm}$.

The PLA particles were coated with a CaP layer by applying a two-step biomimetic procedure as described previously [39,42]. In short, the particles were first immersed in a 2.5 times concentrated Simulated Body Fluid (SBF 2.5 $\times$ ) with ionic content of $733.5 \mathrm{mM} \mathrm{Na}^{2+}, 7.5 \mathrm{mM} \mathrm{Mg}^{2+}, 12.5 \mathrm{mM} \mathrm{Ca}^{2+}, 720 \mathrm{mM} \mathrm{Cl}{ }^{-}, 5 \mathrm{mM}$ $\mathrm{HPO}_{4}^{2-}$ and $21 \mathrm{mM} \mathrm{HCO}_{3}^{-}$, while stirring at $37{ }^{\circ} \mathrm{C}$ for three days with daily refreshment. In the second step, the particles were incubated with a calcium phosphate solution (CPS) consisting of $140 \mathrm{mM}$ $\mathrm{Na}^{2+}, 4 \mathrm{mM} \mathrm{Ca}^{2+}, 2 \mathrm{mM} \mathrm{HPO}_{4}^{2-}$ and $144 \mathrm{mM} \mathrm{Cl}^{-}$(buffered at $\mathrm{pH}$ 7.4), while stirring at $37^{\circ} \mathrm{C}$ for three days with daily refreshments. A stock solution of cobalt chloride (Sigma) in a Tris buffer ( $\mathrm{pH}=7.4$ ) with concentration of $10 \mathrm{mM}$ was prepared. In order to incorporate the ion into CaP coatings, appropriate volumes of $\mathrm{Co}^{2+}$ stock solution were combined with the CPS solution to reach varying concentrations of $\mathrm{Co}^{2+}$ in CPS $(0,0.1$ and $20 \mu \mathrm{M})$. The $\mathrm{Co}^{2+}$ concentrations were selected based on an earlier in vitro study [39] on hypoxia-mimicking by $\mathrm{Co}^{2+}$ to investigate the effect on osteoclastic resorption, which showed a successful incorporation of the ion into CaP using a similar technique. The coated PLA particles were washed three times with MilliQ water, and dried at least overnight in an air oven.

PLA particles were prepared using the same extrusion procedure and served as a control in all the experiments.

\subsection{Material characterization}

The surface morphology and the presence of calcium, phosphorous, carbon and cobalt were investigated on gold-sputtered PLA and CaP-coated PLA particles without $\mathrm{Co}^{2+}$ (CaP-PLA), with low $\mathrm{Co}^{2+}$ concentration (CaP Co0.1-PLA) and with high $\mathrm{Co}^{2+}$ concentration (CaP Co20-PLA) using scanning electron microscopy (SEM, 
XL-30 ESEM-FEG, Philips) in the secondary electron mode, coupled with energy dispersive X-ray spectroscopy analyzer (EDS, EDAX, AMETEK Materials Analysis Division) at the accelerator voltage of $10 \mathrm{keV}$ and working distance of $10 \mathrm{~mm}$. The chemical composition of the particles was characterized using Fourier transform infrared spectroscopy (FTIR, Perkin-Elmer Spectrum 1000) in transmission mode. Furthermore, the total amount of $\mathrm{Co}$, as well as $\mathrm{Ca} / \mathrm{P}$ ratio in CaP-PLA, CaP Co0.1-PLA and CaP Co20-PLA $(\mathrm{n}=3)$ were determined using ICP-MS analysis (Agilent 7700 ICP-MS), upon dissolution of the $\mathrm{CaP}$ coating in ultra-pure nitric acid. Briefly, $1 \mathrm{ml}$ ultra-pure nitric acid ( $10 \mathrm{v} / \mathrm{v} \%$ ) was added to approximately $100 \mu \mathrm{l}$ of particles of each of the four types for approximately $5 \mathrm{~min}$. The solution was then diluted 10 times using MilliQ water, prior to the ICP-MS analysis.

\subsection{Implantation}

Prior to implantation, approximately $1 \mathrm{ml}$ of particles of each PLA, CaP-PLA, CaP Co0.1-PLA and CaP Co20-PLA were sterilized inside histological tissue bags by using ethylene oxide (Isotron Nederland BV). The animal study was approved by the animal ethical committee of the University of Utrecht, Utrecht, The Netherlands (DEC 2012. III.04.040). In total, 10 Dutch milk goats were used for the study. One animal died of pneumonia before the implantations started, and the remaining animals received one implant of each type $(n=9)$. The animals also received other implants, both intramuscularly and on the transverse processes of the lumbar spine. These implantations were not related to this study, and their results will be published separately. The surgical procedures were performed under general anesthesia of the animals, which was achieved and maintained by isoflurane under sterile conditions. Before surgery, the skin of the back of animals was shaved and disinfected with a $10 \%$ povidone-iodine solution. A longitudinal incision followed by a blunt separation was made in the paraspinal area to expose the muscles. Fascia incisions were created in the muscles. Intramuscular pockets were created bilaterally by blunt dissection, and each pocket was filled with approximately $1 \mathrm{ml}$ of the material by using an open syringe. A randomization scheme was used to minimize location-induced effects. Then, fascias were closed with nonresorbable sutures to facilitate implant localization at explantation. The skin was closed in two layers. All animals received a subcutaneous injection of Albipen $^{\circledR}(7.5 \mathrm{ml} / 50 \mathrm{~kg}$, Intervet BV, Boxmeer, the Netherlands) for five consecutive days after surgery to minimize the risk of post-operative infections.

\subsection{Implant retrieval, histological and immunohistochemical evaluation}

Twelve weeks after the implantation, the animals were sacrificed by an overdose of Nembutal ${ }^{\circledR}$ (Apharmo, Arnhem, the Netherlands) and the samples with surrounding tissue were harvested. The explants were stored in $4 \%$ formaldehyde at $4{ }^{\circ} \mathrm{C}$ for at least one week. They were then trimmed to remove the surrounding muscle tissue and each sample was cut into two equal parts, one of which was used for histological and immunohistochemical evaluation of blood vessel formation. For histology, the samples were first decalcified in $125 \mathrm{gr} / \mathrm{l}$ ethylenediaminetetraacetic acid solution (EDTA, Sigma) for one week and then dehydrated using a series of ethanol solutions $(70 \%, 80 \%, 90 \%, 96 \%, 100 \%)$ for at least 5 days per step. They were then placed in polymeric holders, kept in melted paraffin overnight and embedded in paraffin using an automatic embedding apparatus (Excelsior ES, Thermo Scientific). The paraffin blocks were then cut in 5-8 $\mu \mathrm{m}$ thick sections using a microtome (HM355, Microm, Belgium) and dried overnight at room temperature on objective glasses.
Immunohistochemical staining of actin fibers in smooth muscle cells was performed on 4 sections per sample. Briefly, the sections were deparaffinized and rehydrated in xylene and ethanol series, respectively. After washing with milliQ water, the sections were blocked for $1 \mathrm{~h}$ with a blocking solution $(0.5 \mathrm{~W} / \mathrm{V} \%$ bovine serum albumin (BSA) and $0.1 \mathrm{v} / \mathrm{v} \%$ Triton X-100 in PBS). Subsequently, $100 \mu$ Monoclonal Mouse Anti-Human Actin Smooth Muscle antibody (asma, Clone 1A4, Dako, Belgium) diluted in blocking buffer (1:200) was added to each section, and incubated overnight at room temperature in dark. After incubation, the sections were washed with blocking solution, and the anti-goat secondary antibody diluted in blocking solution $(1: 1000)$ was added for $1 \mathrm{~h}$. The sections were then washed twice with PBS and dried in dark in a fume hood for few minutes. The slides were then mounted using a mounting medium containing DAPI to stain the nuclei (VectaShield, Vector Laboratories, Burlingame, USA) prior to imaging using the NanoZoomer both in brightfield mode (data not shown) and in fluorescent mode in DAPI- (data nor shown) and FITC channels.

Hematoxylin and eosin (H\&E, Sigma) staining was performed on 2 sections per sample. In short, the sections were first deparaffinized in xylene (Klinpath) and then rehydrated in a series of ethanol solutions (100\%, 96\%, 90\%, 80\% and 70\%) and stained with hematoxylin solution for $5 \mathrm{~min}$, rinsed with tap water, counterstained with eosin solution for 2 min and fixed in xylene. Masson's trichrome (MT, Merck chemicals) staining was performed on $6 \mathrm{sec}-$ tions per sample. After deparaffinization and rehydration, the sections were stained according to the manufacturer's protocol. The H\&E and the MT stained sections were then mounted on coverslips and dried overnight in a fume hood. The slides were imaged using a NanoZoomer (NanoZoomer 2.0 RS, Hamamatsu, Japan) in the brightfield mode.

The extent of the inflammatory response was evaluated by an experienced pathologist. Randomly selected H\&E-stained slides of each sample type from all animals were used for scoring the presence of inflammatory cells in the connective tissue between the material particles as well as in the connective tissue around the implant. When $40-60 \%$ of the connective tissue contained inflammatory cells, the sample received score 2 . Samples with inflammatory cells present in less than $40 \%$ of the connective tissue area received score 1 , and above $60 \%$, score 3.

Number of blood vessels and blood vessel area were quantified on 6 MT-stained slides per sample selected from different areas ( 2 from the top, 2 from the middle and 2 from the bottom). Quantification of the blood vessel area per sample area was performed using Adobe Photoshop CS6 by first determining the sample area (per pixel) and then manually selecting and quantifying the red-stained area (per pixel). Quantification of the vessel number was done semi-automatically by using ImageJ 1.48 by first adjusting the color thresholds to eliminate the noise of the background and then quantifying the number of cells. The results were then normalized for the sample area and presented as number of vessels per 1000 pixels area.

\subsection{Statistical analysis}

For the statistical analysis of the scores for inflammatory response to the four material types, the Kruskal-Wallis test was performed. Histomorphometrical data on blood vessel area and blood vessel number were analyzed by using the One-way Analysis of Variance (ANOVA) followed by a Tukey's multiple comparison post hoc test. Differences were considered statistically significant at $\mathrm{p}<0.05$. 
a1

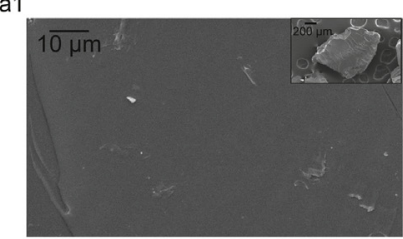

a2

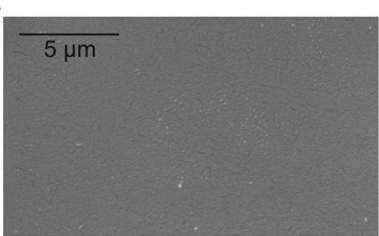

a3

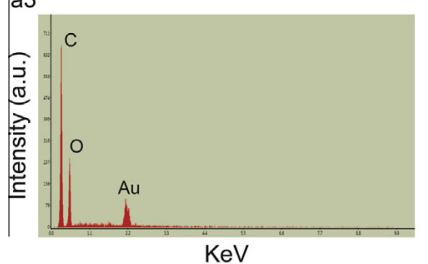

b1

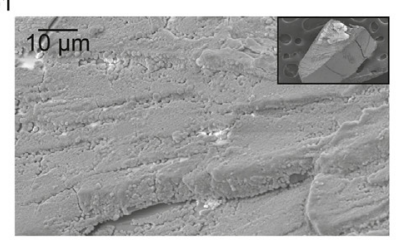

b2

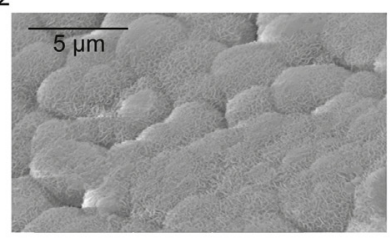

b3

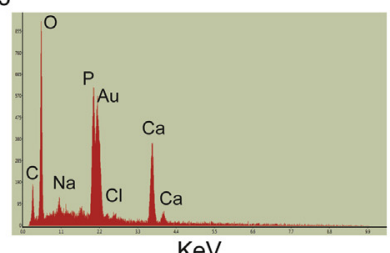

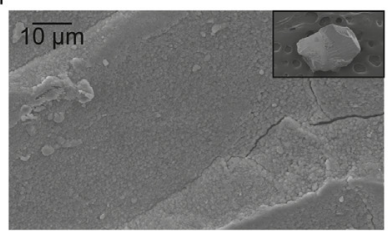
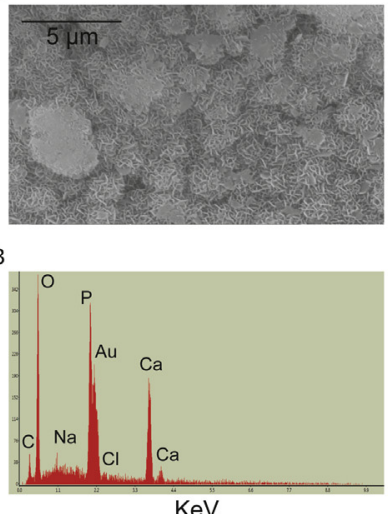

d1

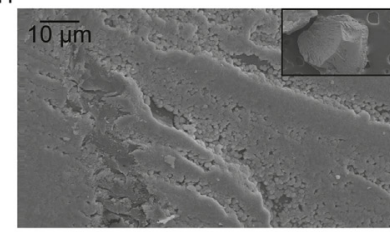

d2

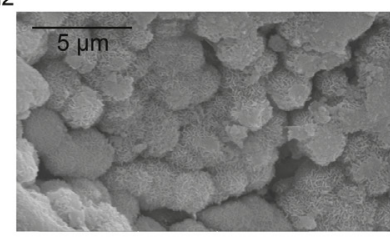

d3

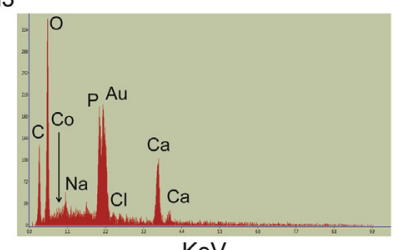

e

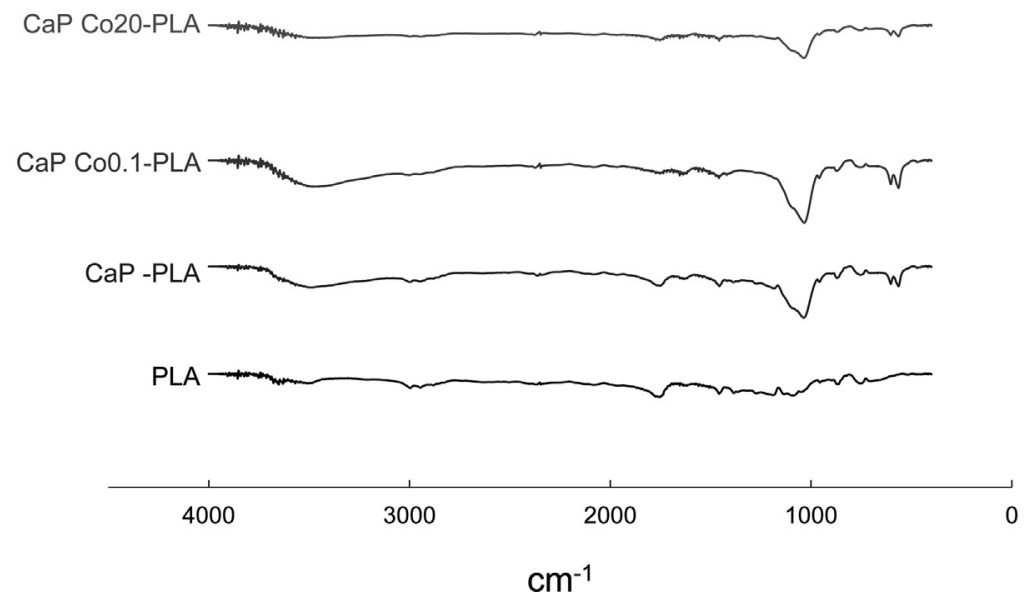

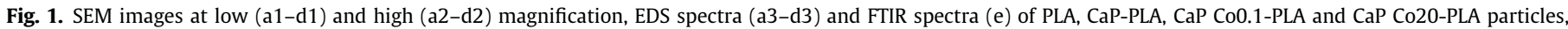

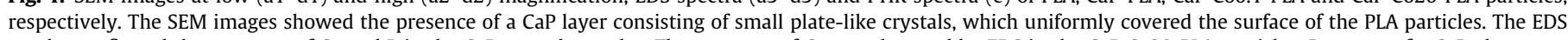

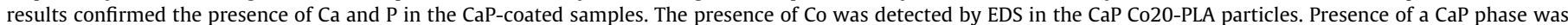
further confirmed by the FTIR analysis.

\section{Results}

\subsection{Material characterization}

The extrusion-grinding technique used for the production of implants resulted in the formation of irregularly shaped dense PLA particles with a diameter of $0.5-1 \mathrm{~mm}$ (Fig. 1a1-d1, insets). Upon the two-step biomimetic coating process, a uniform mineral layer was formed on the surface of PLA particles, covering it completely. Addition of $\mathrm{Co}^{2+}$ to the CPS solution did not prevent the formation of the mineral coating on the particles. Microscopically, while the PLA particles exhibited a relatively smooth surface, the CaP-coated particle surface appeared rougher and more porous. The coating consisted of mineral globules with a diameter below $1 \mu \mathrm{m}$ that were built of small plate-shaped crystals. The presence of $\mathrm{Co}^{2+}$ in CPS solution did not have an obvious effect on the size or the morphology of the crystals (Fig. 1a1-d2). The EDS analysis showed a decrease in the intensity of the carbon peak on the surface of the coated PLA particles as compared to the uncoated PLA. This was accompanied by the appearance of the calcium and phosphorous peaks and an increase in the intensity of oxygen, suggesting the formation of a CaP phase on the surface of PLA particles. A small peak of Co could be detected only at higher concentrations, being the CaP Co20-PLA sample. Appearance of sodium and chlorine peaks in the EDS spectra of CaP-coated PLA particles indicated the presence of residual $\mathrm{NaCl}$ in the coating, suggesting incomplete washing (Fig. 1a3-d3).

FTIR analysis of the PLA particles without coating (Fig. 1e) showed typical spectrum of pure PLA, including the bands at approximately $1000-1100 \mathrm{~cm}^{-1}$ that corresponded to the stretching mode of $\mathrm{C}-\mathrm{O}$ bond, at $1370-1450$ and $1950-2000 \mathrm{~cm}^{-1}$ corresponding to bending and stretching modes, and at $1750 \mathrm{~cm}^{-1}$ that is attributed to stretching mode of $\mathrm{C}=\mathrm{O}$ bond [44-46].

Similar peaks were observed in the FTIR spectra of all CaPcoated PLA particles. The $\mathrm{C}-\mathrm{O}$ band at $1000 \mathrm{~cm}^{-1}$ was however modified in these samples due to the presence of $\mathrm{PO}_{4}^{3-}$ peak at sim- 
ilar wavelength $[43,46]$. The bands at 560 and $604 \mathrm{~cm}^{-1}$ in the FTIR spectra of all CaP-coated PLA particles also corresponded to the $\mathrm{P}-\mathrm{O}$ bond. The small shoulder at $3565 \mathrm{~cm}^{-1}$ formed on $\mathrm{H}_{2} \mathrm{O}$ band at approximately $3500 \mathrm{~cm}^{-1}$ is attributed to the hydroxyl group. These results confirmed the presence of a CaP coating on the surface of PLA particles independent of the concentration of $\mathrm{Co}^{2+}$ in the CPS solution.

ICP-MS analysis of the coatings dissolved in nitric acid indicated that the amount of Co in the CaP-coated PLA was below $0.01 \mathrm{mg} / \mathrm{L}$, whereas in the CaP Co0.1-PLA and CaP Co20-PLA, the amount was $0.39 \pm 0.02 \mathrm{mg} / \mathrm{l}$ and $2.76 \pm 0.21 \mathrm{mg} / \mathrm{l}$, respectively. The $\mathrm{Ca} / \mathrm{P}$ ratio of CaP Co0.1-PLA and ( $\mathrm{Ca}+\mathrm{Co}) / \mathrm{P}$ ratios of CaP Co0.1-PLA and CaP Co20-PLA were $1.27 \pm 0.01,1.29 \pm 0.01$ and $1.28 \pm 0.01$, respectively.

\subsection{Histological and immunohistochemical analyses}

No surgical complications occurred and all animals showed an uneventful recovery from the surgery. At implant retrieval, no visual signs of inflammation or infection, such as redness or swelling, were observed. Representative images of H\&E stained tissue sections from one animal (goat \#1), showing the overall histological appearance of the implants and the newly formed tissue are presented in Fig. 2. Newly formed soft tissue was observed between the material particles in all cases, with normal cell distribution. No apparent bulk degradation of any of the particles occurred, and the size of the particles remained in the range of $0.5-1 \mathrm{~mm}$.

Pathological analysis of the inflammatory response indicated the presence of macrophages, plasma cells and T-cells, suggesting a mild chronic inflammatory response. The majority of inflammatory cells were observed in the connective tissue surrounding the implants, close to blood vessels, while fewer inflammatory cells were observed in the connective tissue that was formed between individual particles (Fig. 2a2-d2). The scores of the extent of inflammatory response are shown in Table 1 . No significant differences in the extent of inflammatory response were found between the four material types $(\mathrm{p}=0.714)$.
Table 1

Pathological scores of the inflammatory response to the four materials following 12 weeks of implantation.

\begin{tabular}{lllll}
\hline $\begin{array}{l}\text { Inflammatory } \\
\text { response } \\
\text { score }\end{array}$ & $\begin{array}{l}\text { PLA } \\
\text { (number of } \\
\text { animals) }\end{array}$ & $\begin{array}{l}\text { CaP-PLA } \\
\text { (number of } \\
\text { animals) }\end{array}$ & $\begin{array}{l}\text { CaP0.1Co-PLA } \\
\text { (number of } \\
\text { animals) }\end{array}$ & $\begin{array}{l}\text { CaP20Co-PLA } \\
\text { (number of } \\
\text { animals) }\end{array}$ \\
\hline $1(<40 \%)$ & 1 & 2 & 4 & 3 \\
$2(40-60 \%)$ & 5 & 5 & 2 & 5 \\
$3(>60 \%)$ & 1 & 0 & 2 & 0 \\
\hline
\end{tabular}

Immunohistochemical analysis was performed to locate actin fibers that are present in the smooth muscle cells' cytoskeleton. The representative results of this analysis for 3 animals (goats $\# 1, \# 2$ and \#3) are shown in Fig. 3. Because of the autofluorescence of the materials, especially at the interface with soft tissue, the immunohistochemical analysis could not be reliably used for the quantification of blood vessel parameters. Nevertheless, the images clearly illustrated the presence of blood vessels with high fluorescence intensity and a hollow circular or elliptical morphology. Cell nuclei were detected in the DAPI channel at the same location, and were arranged in the same circular or elliptical shape (data not shown). The results of the immunohistochemical analysis showed the presence of small blood vessels in low numbers in PLA and CaP-PLA samples. On the other hand, the blood vessels found around $\mathrm{CaP}$ Co0.1-PLA and $\mathrm{CaP}$ Co 20-PLA particles were in general larger in size and appeared in larger numbers.

Fig. 4a1-d3 exhibits representative results of the MT staining for one animal (goat \#1), with host muscle tissue surrounding the implant, and newly formed fibrous tissue infiltrating the space between material particles. The formation of blood vessels inside the tissue was confirmed by the presence of erythrocytes. Qualitative analysis of the MT-stained sections was in accordance with the results of immunohistochemical analysis and indicated that in general, fewer, and smaller blood vessels were formed around the PLA and CaP-PLA particles in most animals. On the other hand, in CaP a1

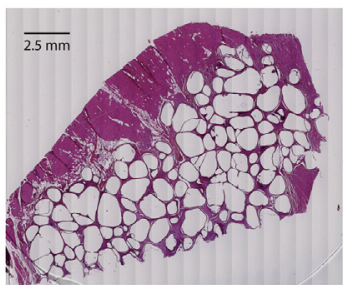

a2

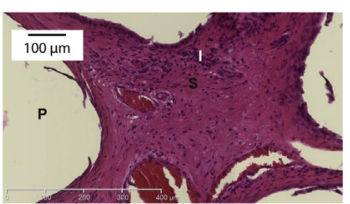

a3

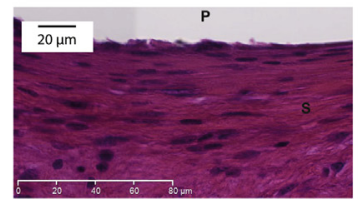

b1

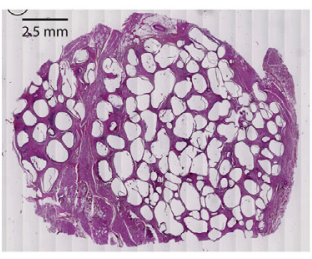

b2

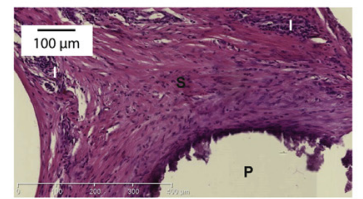

b3

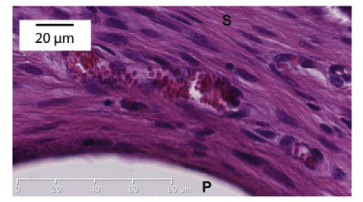

c1

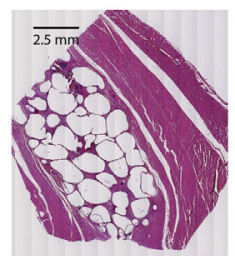

C2

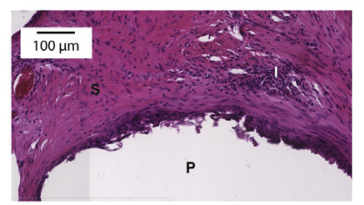

c3

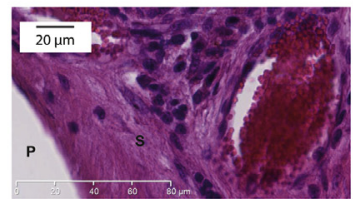

d1

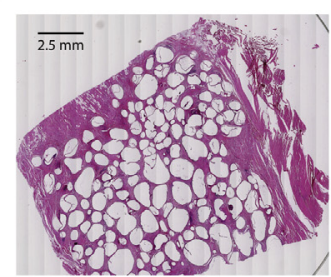

$\mathrm{d} 2$

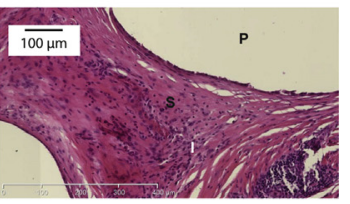

d3

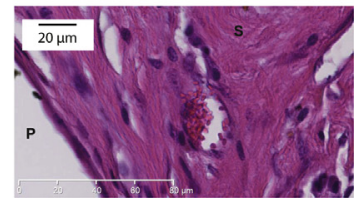

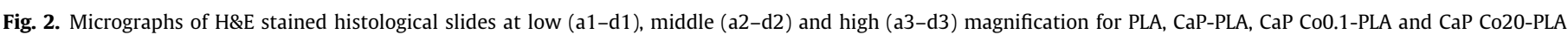

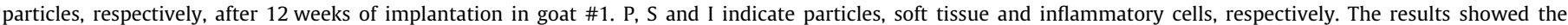

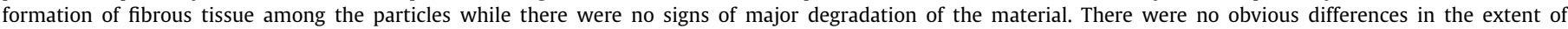
inflammatory response between the four types of materials. 
a1

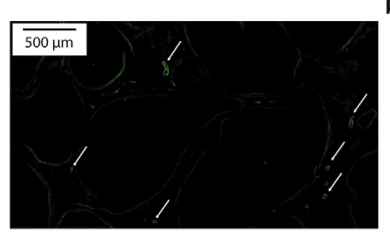

b1

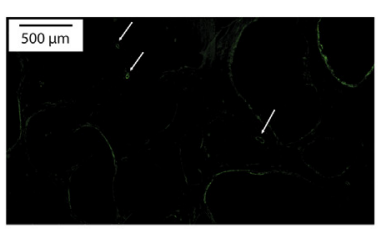

C1

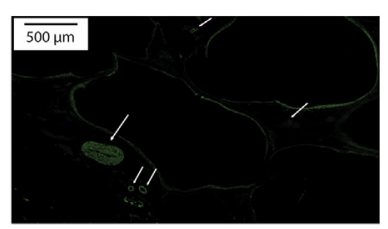

d1

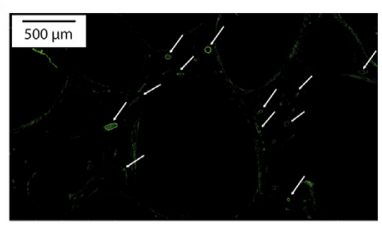

d2

C2
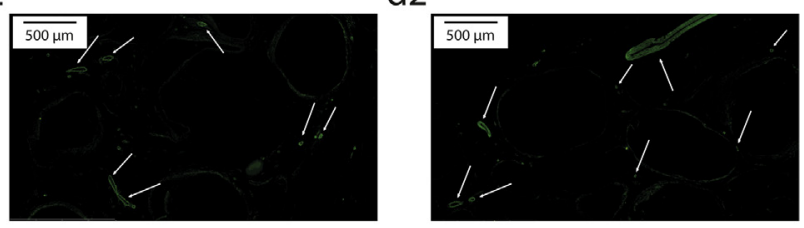

C3

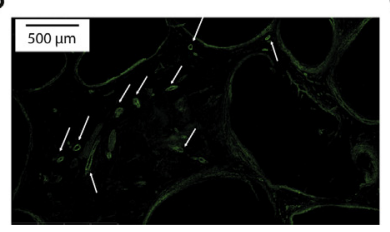

d3

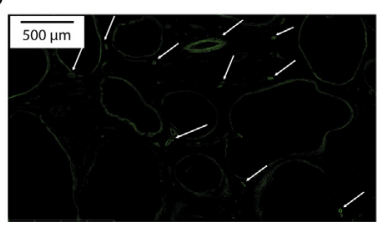

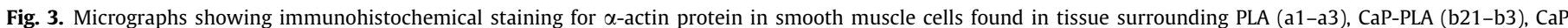

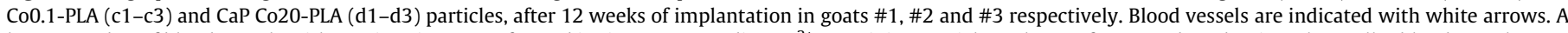

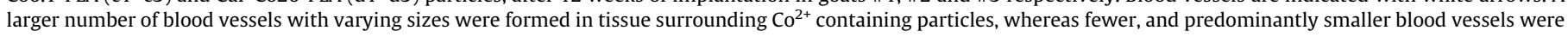
formed in association with PLA and CaP-coated PLA particles.

Co0.1-PLA and CaP Co20-PLA samples, the blood vessels density was higher, and the average size of the vessels larger.

These qualitative observations were confirmed by the quantification of the average number of blood vessels and their area, normalized for the sample area, that was performed on all samples (Fig. 4e and f). In detail, the normalized blood vessel area was significantly higher in CaP-coated PLA particles containing $\mathrm{Co}^{2+}$ as compared to PLA and CaP-PLA particles. A similar trend was observed for blood vessel number. While a significantly higher number of blood vessels was observed in Co0.1-PLA and Co20PLA samples when compared to PLA-CaP, the only significant difference was between PLA and Co0.1-PLA.

The distribution of the blood vessel size for each sample is shown in Fig. 5. Small vessels (vessel area $<0.01 \mathrm{~mm}^{2}$ ) were found in similar numbers in all the samples. A clear difference in the frequency of occurrence of intermediate size blood vessels $\left(0.01 \mathrm{~mm}^{2}<\right.$ vessel area $\left.<0.05 \mathrm{~mm}^{2}\right)$ was observed between samples with and without $\mathrm{Co}^{2+}$. Extra-large vessels (vessel area $>0.05 \mathrm{~mm}^{2}$ ) were rarely present in PLA (Fig. 5a) and CaPPLA (Fig. 5b) samples, while they were frequently observed in $\mathrm{Co}^{2+}$ incorporated samples (Fig. $5 \mathrm{c}$ and $\mathrm{d}$ ), especially at higher $\mathrm{Co}^{2+}$ concentration (Fig. $5 \mathrm{~d}$ ).

\section{Discussion}

The focus of this study was localized delivery of $\mathrm{Co}^{2+}$ ions to stimulate new blood vessel formation in vivo. $\mathrm{Co}^{2+}$ ions are known chemical mimickers of hypoxia, and their application has previously been shown to result in a higher expression of angiogenic genes $[47,48]$. Indeed, hypoxic conditions stimulate angiogenesis, with HIFs playing an important role in this mechanism [49,50]. The upregulation of the expression of angiogenic factors such as VEGF and osteoprotegerin (OPG), and enhancement of vascularization, are known biological responses to hypoxic conditions [22]. Furthermore, hypoxia also affects other aspects of angiogenesis such as vessel pattern, maturation and function [50]. With this important role in mind, hypoxia has been investigated as a strategy to improve angiogenesis in bone graft substitutes [51,52].
Building up on the previously shown effect of $\mathrm{Co}^{2+}$ on angiogenesis, we hypothesized that combining CaPs, being widely used synthetic bone graft substitutes, with $\mathrm{Co}^{2+}$ ions is a promising approach to simultaneously stimulate both osteogenesis and angiogenesis during bone regeneration. A CaP coating with or without $\mathrm{Co}^{2+}$ was applied on a polymeric substrate. The rationale behind the combination of a polymeric substrate and a ceramic coating was the strategy to improve the mechanical properties of the ceramic while retaining the bioactivity, a topic that will be discussed separately.

In the current study, paraspinal muscles of goats were used as the implantation site to first deliver evidence for an effect and select the right conditions, before moving to a bone defect, the number of which is limited in such an animal model. The intramuscular environment is obviously different from the microenvironment in a bone defect, and the response to the materials tested here may be different in bone. Nevertheless, assessment of newly developed materials in vivo in a large animal model provides valuable information that is complementary to in vitro studies or studies in smaller animals, owing to a closer resemblance of larger animals to human skeletal structure and metabolism. Furthermore, based on an earlier study in which cobalt-substituted CaP was tested in osteoporotic bone in vivo [28], a positive effect of $\mathrm{Co}^{2+}$ ions on blood vessel formation is expected in bone as well.

The method used to incorporate $\mathrm{Co}^{2+}$ ions into CaP coatings is based on precipitation of the mineral from a CaP solution to which the ion was added at near physiological conditions. This allows for the incorporation throughout the coating, and not only on the surface, as is the case with adsorption-based methods [39,42]. This approach has been previously shown to result in a more controlled release of incorporated compounds, such as Bone Morphogenetic Protein-2 [53]. Here, we successfully deposited a homogenous mineral layer on the surface of PLA particles, both in absence and in presence of $\mathrm{Co}^{2+}$. Patntirapong et al. [39] coated the surface of tissue culture well plates with CaP with or without $\mathrm{Co}^{2+}$ to study the effect of $\mathrm{Co}^{2+}$ on osteoclastic resorption of the mineral. Their results showed the formation of a CaP coating with a similar crystal morphology, which was shown to predominantly consist of octa- 
a1

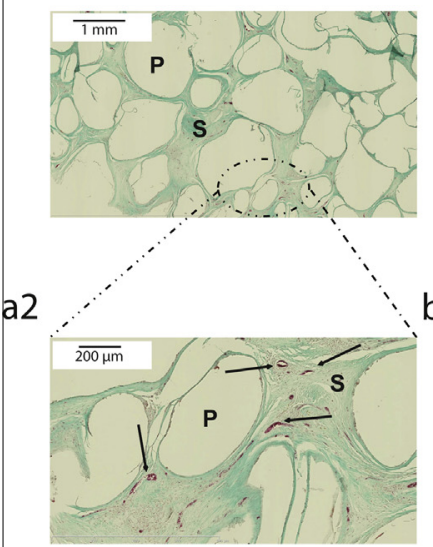

a3

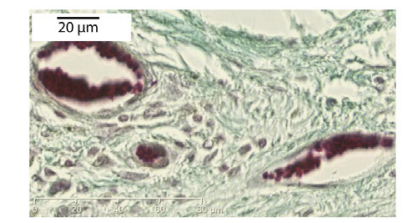

b1
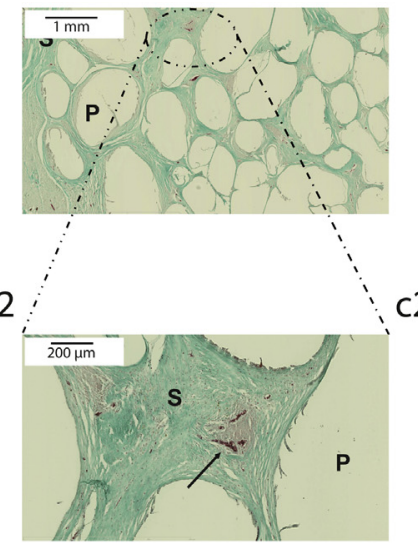

b3

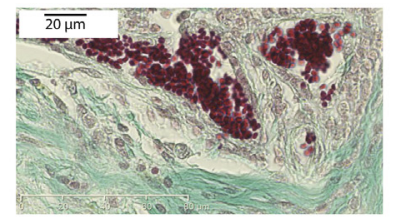

C1

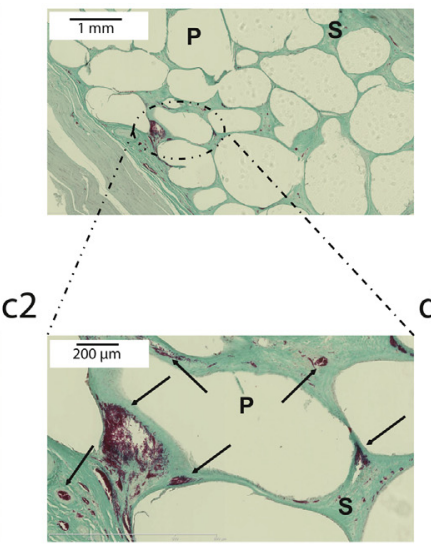

c3

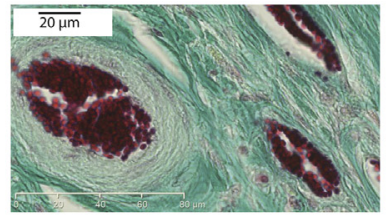

d1

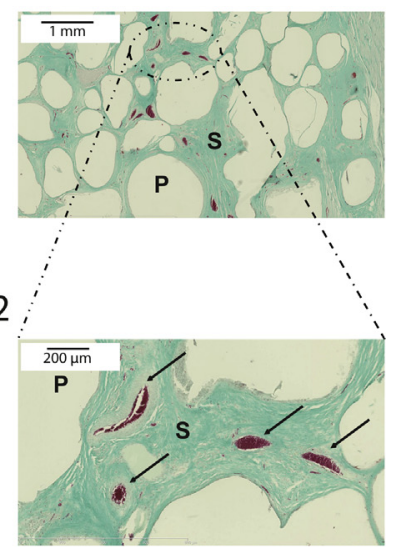

d3

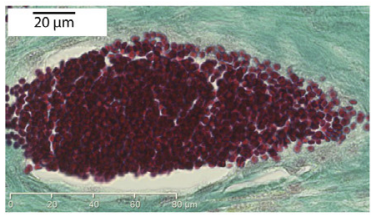

e

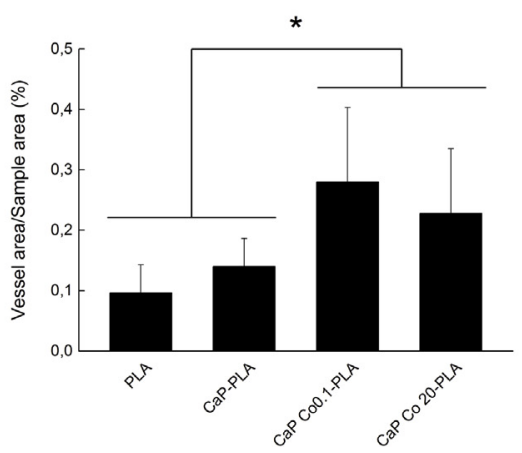

f

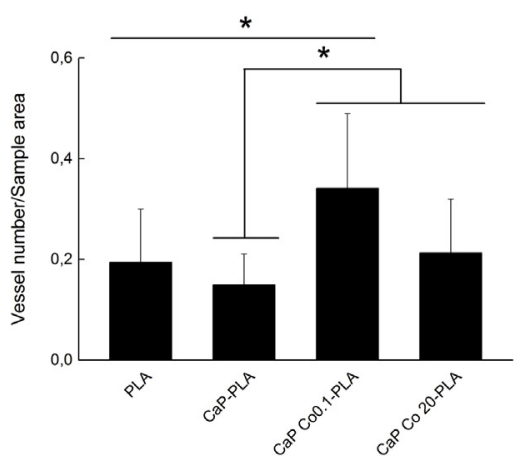

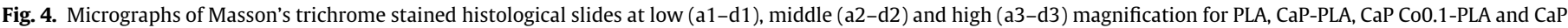

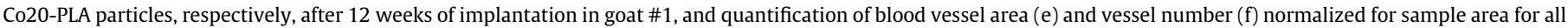

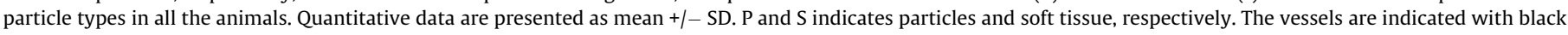

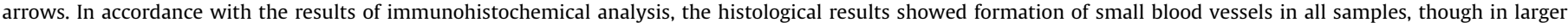

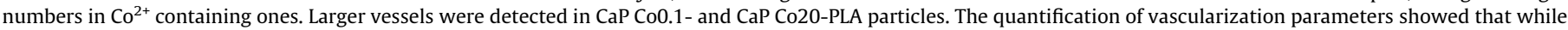

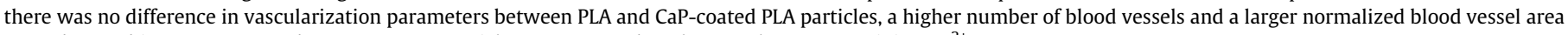
were detected in CaP Co0.1- and CaP Co20-PLA particles as compared to the samples not containing $\mathrm{Co}^{2+}$.

calcium phosphate (OCP). In our study, the difference in $\mathrm{Co}^{2+}$ concentration between the two $\mathrm{Co}^{2+}$ containing coating solutions was 200 times. The Co content of CaP Co20-PLA, however, was only 7 times higher than that of CaP Co0.1, which suggests that there is a maximum amount of the ion that can be incorporated into the $\mathrm{CaP}$ coating. Nevertheless, the $\mathrm{Ca} / \mathrm{P}$ ratio of the coating without $\mathrm{Co}^{2+}$ and the $(\mathrm{Ca}+\mathrm{Co}) / \mathrm{P}$ ratios of the coatings with $\mathrm{Co}^{2+}$ indicated that the nucleation and growth of the crystals were not affected by the presence of $\mathrm{Co}^{2+}$, which was also confirmed by the SEM and FTIR analyses. Partial Co-for-Ca substitution has been previously shown in $\beta$-tricalcium phosphate [54], however, based on our data it is difficult to conclude whether all the incorporated Co was actually substituted into the CaP lattice or partially physically entrapped into the coating.

After 12 weeks of intramuscular implantation, the formation of fibrous tissue was detected in the pores between the material particles. The results further evidenced that there was no major bulk degradation of the PLA particles with or without the CaP coating. This is in contrast to the results by Danoux et al. [43] where a substantial degradation of PLA plates prepared using a similar technique was observed after 12 weeks of intramuscular implantation in dogs. This difference could be attributed to the physiological differences between the two species, as well as the difference in the implant shape. Because the materials were decalcified after explantation, we could not determine the level of degradation of the CaP coating. In a study by Barrere et al., it was shown that an OCP coating that was deposited on titanium plates did not dissolve after 4 weeks of subcutaneous implantation in rats, but instead transformed into a more stable carbonated apatite phase [55]. Although useful, this data cannot be directly extrapolated to our study, because of the difference in the animal model and in implantation period. It was also not possible to measure the release profile of $\mathrm{Co}^{2+}$ in vivo. Nevertheless, the in vitro study by Patntirapong et al. [39] showed that in cell culture medium, a burst release of $\mathrm{Co}^{2+}$ was observed from CaP coatings deposited on cell culture plastic. After 3 days, about $50 \%$ of total $\mathrm{Co}^{2+}$ was released, and after 6 days another $5 \%$ release was measured. Although the environment of a cell culture dish is very different from that 

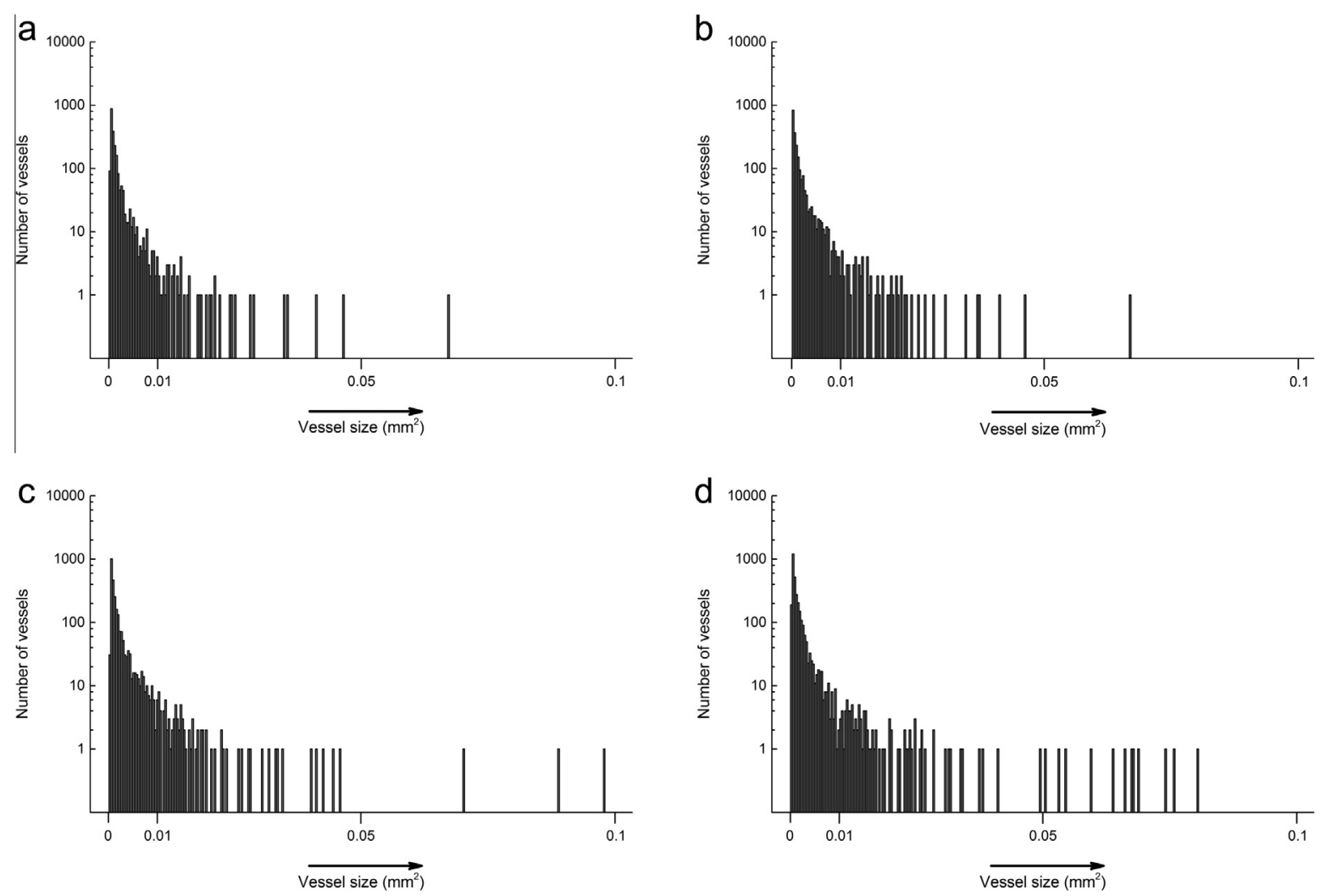

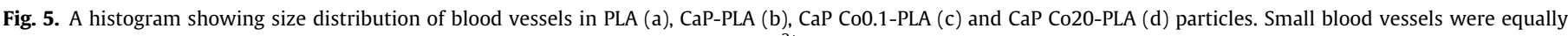

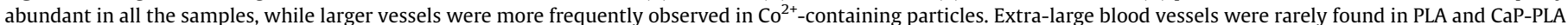

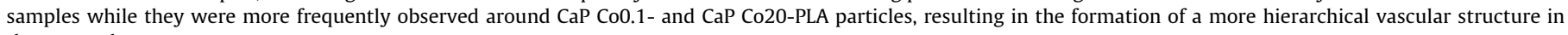
these samples.

in vivo, this suggests that the majority of the ions are released relatively soon after implantation.

Both histological and immunohistochemical analyses showed the formation of small blood vessels, with a size below $0.01 \mathrm{~mm}^{2}$, in low numbers in the tissue formed around PLA and CaP-PLA particles. In the CaP Co0.1- and CaP Co20-PLA samples both small and larger vessels were frequently found. In accordance with these results, quantification of blood vessel area and number of vessels showed higher values for both parameters for $\mathrm{Co}^{2+}$ containing materials as compared to both controls. Fan et al. [29] demonstrated that treating bone marrow stromal cells (BMSCs) with $\mathrm{Co}^{2+}$ ions resulted in a more pronounced vascularization of collagen scaffolds, in which the cells were incorporated, upon a 2-week subcutaneous implantation in mice. Subsequent implantation of these scaffolds in an orthotopic site resulted in enhanced neovascularized bone formation. Ignjatović et al. [28] also analyzed the effect of paramagnetic cobalt-substituted hydroxyapatite (HA) nanoparticles on osteoporotic alveolar bone regeneration and blood vessel formation in rats. The results showed an active process of angiogenesis and bone formation 6 and 24 weeks after the implantation of the nanoparticles containing $\mathrm{Co}^{2+}$. The in vitro studies showed that treatment of BMSCs with $\mathrm{Co}^{2+}$ ions increased the expression of VEGF both at mRNA and protein level $[27,29]$. In a more recent study, Quinlan et al. [56] demonstrated that the incorporation of cobalt in bioactive glass significantly enhanced the production and expression of VEGF by endothelial cells. Furthermore, they observed that exposing endothelial cells to cell medium conditioned with cobalt incorporated-bioactive glass/collagen glycosaminoglycan scaffold enhanced the tubule formation. In accordance with these previous studies, our findings also indicated that while there was no difference in vascularization between the PLA and CaP-coated PLA particles, incorporation of $\mathrm{Co}^{2+}$ in the CaP coatings enhanced the vascularization in terms of number of blood vessels and their area.

As a relatively long implantation time was selected in this study, early events that may mechanistically explain the positive effect of $\mathrm{Co}^{2+}$ on vascularization cannot be determined. While we hypothesize that local hypoxic environment may be a reason for increased vascularization, short-term implantation is needed to analyze the HIF-1 $\alpha$ expression in the surrounding tissue. Furthermore, besides the effect of hypoxia, increased inflammatory responses to the $\mathrm{Co}^{2+}$-containing materials may be a reason for the enhanced vascularization. Although the pathological analysis after 12 weeks indicated the presence of a mild chronic inflammatory response in the connective tissue surrounding all materials, no significant differences between the four implant types were observed. These findings suggest that increased vascularization was not a result of an increased inflammatory response. Regardless, it is important to analyze early events upon implantation of such materials, and appreciate the release of $\mathrm{Co}^{2+}$ from them. Additionally, adequate investigation is needed on how tissues are affected by a sustained release of $\mathrm{Co}^{2+}$. This is particularly important from the safety perspective, as in vitro studies have shown a negative effect on viability upon prolonged exposure of cells to cobalt-substituted hydroxyapatite [28].

The results of this study showed that incorporation of $\mathrm{Co}^{2+}$ not only increased the number of blood vessels and their area, but also their size distribution. Blood vessels of different sizes ranging from very large ones with the area larger than $0.05 \mathrm{~mm}^{2}$, to small vessels with an average area below $0.01 \mathrm{~mm}^{2}$, were formed when $\mathrm{Co}^{2+}$ was present in the CaP coating. In contrast, in the samples without $\mathrm{Co}^{2+}$, with or without $\mathrm{CaP}$, very large vessels did not form 
and large vessels were less frequent. Similar to this observation, Ignjatović et al. [28] detected the formation of a properly structured vascular network containing both large blood vessels and small capillaries in HA nanoparticles with $\mathrm{Co}^{2+}$ incorporation when implanted in rats. The importance of the size of blood vessels is evident considering that natural bone is highly vascularized from the intramedullary cavity to the periosteal mineral, with a hierarchical vascular structure containing large vessels which further branch out internally into small capillaries [4].

Based on the previously published work, a hypoxic environment induced by $\mathrm{Co}^{2+}$ may have an important effect on the vascular pattern and lumen size of the newly formed blood vessels. It is known that local metabolic and mechanical changes in cell microenvironment, including the presence of hypoxic conditions, substantially influence the formation, maturation, function and remodeling of the vessels of different sizes [50,57]. Stoeltzing et al. [58] studied the effects of inhibition of HIF- $1 \alpha$ activity on angiogenesis in human gastric cancer in vivo and observed the formation of blood vessels with much smaller lumen size in the tumor cells, in which the HIF- $1 \alpha$ activity was inhibited compared to those expressing increased level of HIF- $1 \alpha$. They suggested that HIF- $1 \alpha$ provided a complex proangiogenic microenvironment that influences vessel morphology and function. Based on this argument, the upregulation of HIF- $1 \alpha$ in the muscle tissue as a result of $\mathrm{Co}^{2+}$-induced hypoxia may indeed plausibly be the reason for larger lumen size and different vascular structure in the presence of these ions.

\section{Conclusion}

This study demonstrated that incorporation of $\mathrm{Co}^{2+}$ into a $\mathrm{CaP}$ coating resulted in the formation of more and larger blood vessels upon intramuscular implantation in goats. Also, a wider distribution in size of blood vessels was achieved in the presence of $\mathrm{Co}^{2+}$. As such, these results support the use of $\mathrm{Co}^{2+}$-containing $\mathrm{CaPs}$ as a means to stimulate vascularization of synthetic bone graft substitutes.

\section{Acknowledgements}

This research forms part of the Project P2.04 BONE-IP of the research program of the BioMedical Materials institute, cofunded by the Dutch Ministry of Economic Affairs, Agriculture and Innovation. The study was sponsored by the Perfectos research grant from Agentschap NL and has been in part made possible with the support of the Dutch Province of Limburg.

\section{References}

[1] H. Gerber, N. Ferrara, Angiogenesis and bone growth, Trends Cardiovasc. Med. 10 (2000) 223-228.

[2] R.A.D. Carano, E.H. Filvaroff, Angiogenesis and bone repair, Drug Discov. Today 8 (2003) 980-989.

[3] M.R. Hausman, M.B. Schaffler, R.J. Majeska, Prevention of fracture healing in rats by an inhibitor of angiogenesis, Bone 29 (2001) 560-564.

[4] A.E. Mercado-Pagán, A.M. Stahl, Y. Shanjani, Y. Yang, Vascularization in bone tissue engineering constructs, Ann. Biomed. Eng. 43 (2015) 718-729.

[5] M.W. Laschke, M.D. Menger, Vascularization in tissue engineering: angiogenesis versus inosculation, Eur. Surg. Res. 48 (2012) 85-92.

[6] M. Lovett, K. Lee, A. Edwards, D.L. Kaplan, Vascularization strategies for tissue engineering, Tissue Eng. Part B 15 (2009) 353-370.

[7] L.H. Nguyen, N. Annabi, M. Nikkhah, H. Bae, L. Binan, S. Park, Y. Kang, Y. Yang, A. Khademhosseini, Vascularized bone tissue engineering: approaches for potential improvement, Tissue Eng. Part B 18 (2012) 363-382.

[8] Y. Chiu, M. Cheng, H. Engel, S. Kao, J.C. Larson, S. Gupta, E.M. Brey, The role of pore size on vascularization and tissue remodeling in PEG hydrogels, Biomaterials 32 (2011) 6045-6051.

[9] D. Kaigler, Z. Wang, K. Horger, D.J. Mooney, P.H. Krebsbach, VEGF scaffolds enhance angiogenesis and bone regeneration in irradiated osseous defects, J. Bone Miner. Res. 21 (5) (2006) 735-744.
[10] A. Kampman, D. Lindhorst, P. Schumann, R. Zimmerer, H. Kokemüller, M. Rücker, N. Gellrich, F. Tavassol, Additive effect of mesenchymal stem cells and VEGF to vascularization of PLGA scaffolds, Microvasc. Res. 90 (2013) 71-79.

[11] E. Wernike, M.O. Montjovent, Y. Liu, D. Wismeijer, E.B. Hunziker, K.-A. Siebenrock, W. Hofstetter, F.M. Klenke, VEGF incorporation into calcium phosphate ceramics promotes vascularization and bone formation in vivo, Eur. Cells Mater. 19 (2010) 30-40.

[12] D. Qu, J. Li, Y. Li, Y. Gao, Y. Zuo, Y. Hsu, J. Hu, Angiogenesis and osteogenesis enhanced by bFGF ex vivo gene therapy for bone tissue engineering in reconstruction of calvarial defects, J. Biomed. Mater. Res. A 96 (2011) $543-551$.

[13] J. Rouwkema, J. de Boer, C.A. van Blitterswijk, Endothelial cells assemble into a 3-dimensional prevascular network in a bone tissue engineering construct, Tissue Eng. 12 (2006) 2685-2693.

[14] G.E. Amiel, M. Komura, O. Shapira, J.J. Yoo, S. Yazdani, J. Berry, S. Kaushal, J. Bischoff, A. Atala, S. Soker, Engineering of blood vessels from acellular collagen matrices coated with human endothelial cells, Tissue Eng. 12 (2006) 23552365.

[15] C.S.N. Choong, D.W. Hutmacher, J.T. Triffitt, Co-culture of bone marrow fibroblasts and endothelial cells on modified polycaprolactone substrates for enhanced potentials in bone tissue engineering, Tissue Eng. 12 (2006) 25212531.

[16] N. Von Offenberg Sweeney, P.M. Cummins, E.J. Cotter, P.A. Fitzpatrick, Y.A. Birney, E.M. Redmond, P.A. Cahill, Cyclic strain-mediated regulation of vascular endothelial cell migration and tube formation, Biochem. Biophys. Res. Commun. 329 (2005) 573-582.

[17] T. Iba, B.E. Sumpio, Morphological response of human endothelial cells subjected to cyclic strain in vitro, Microvasc. Res. 42 (1991) 245-254.

[18] Q. Li, T. Hou, J. Zhao, J. Xu, Vascular endothelial growth factor release from alginate microspheres under simulated physiological compressive loading and the effect on human vascular endothelial cells, Tissue Eng. Part A 17 (2011) $1777-1785$.

[19] N. Rahimi, D.G. Molin, T.J. Cleij, M.A. van Zandvoort, M.J. Post, Electrosensitive polyacrylic acid/fibrin hydrogel facilitates cell seeding and alignment, Biomacromolecules 13 (2012) 1448-1457.

[20] J.T. Borenstein, H. Terai, K.R. King, E.J. Weinberg, M.R. Kaazempur-Mofrad, J.P. Vacanti, Microfabrication technology for vascularized tissue engineering, Biomed. Microdevices 4 (2002) 167-175.

[21] J. Doorn, H.A.M. Fernandes, B.Q. Le, J. van de Peppel, J.P.T.M. van Leeuwen, M.R. De Vries, Z. Aref, P.H.A. Quax, O. Myklebost, D.B.F. Saris, C.A. van Blitterswijk, J. de Boer, A small molecule approach to engineering vascularized tissue, Biomaterials 34 (2013) 3053-3063.

[22] S. Bose, G. Fielding, S. Tarafder, A. Bandyopadhyay, Understanding of dopantinduced osteogenesis and angiogenesis in calcium phosphate ceramics, Trends Biotechnol. 31 (10) (2013) 594-605.

[23] A. Grosfeld, V. Zilberfar, S. Turban, J. André, M. Guerre-Millo, T. Issad, Hypoxia increases leptin expression in human PAZ6 adipose cells, Diabetologia 45 (2002) 527-530.

[24] F. Grasselli, G. Basini, S. Bussolati, F. Bianco, Cobalt chloride, a hypoxiamimicking agent, modulates redox status and functional parameters of cultured swine granulosa cells, Reprod. Fertil. Dev. 17 (2005) 715-720.

[25] C.J. Schofield, P.J. Ratcliffe, Oxygen sensing by HIF hydroxylases, Nat. Rev. Mol. Cell. Biol. 5 (2004) 343-354.

[26] G.L. Semenza, HIF-1 and mechanisms of hypoxia sensing, Curr. Opin. Cell. Biol. 13 (2001) 167-171.

[27] C. Wu, Y. Zhou, W. Fan, P. Han, J. Chang, J. Yuen, M. Zhang, Y. Xiao, Hypoxiamimicking mesoporous bioactive glass scaffolds with controllable cobalt ion release for bone tissue engineering, Biomaterials 33 (2012) 2076-2085.

[28] N. Ignjatović, Z. Ajduković, V. Savić, S. Najman, D. Mihailović, P. Vasiljević, Z. Stojanović, V. Uskoković, D. Uskoković, Nanoparticles of cobalt-substituted hydroxyapatite in regeneration of mandibular osteoporotic bones, J. Mater. Sci. Mater. Med. 24 (2013) 343-354

[29] W. Fan, R. Crawford, Y. Xiao, Enhancing in vivo vascularized bone formation by cobalt chloride-treated bone marrow stromal cells in a tissue engineered periosteum model, Biomaterials 31 (2010) 3580-3589.

[30] A. Bigi, G. Cojazzi, S. Panzavolta, A. Ripamonti, N. Roveri, M. Romanello, K. Noris Suarez, L. Moro, Chemical and structural characterization of the mineral phase from cortical and trabecular bone, J. Inorg. Biochem. 68 (1997) 45-51.

[31] A.J. Wagoner Johnson, B.A. Herschler, A review of the mechanical behavior of $\mathrm{CaP}$ and $\mathrm{CaP} /$ polymer composites for applications in bone replacement and repair, Acta Biomater. 7 (2011) 16-30.

[32] C. Canal, M.P. Ginebra, Fibre-reinforced calcium phosphate cements: a review, J. Mech. Behav. Biomed. Mater. 4 (2011) 1658-1671.

[33] P. Habibovic, M.C. Kruyt, M.V. Juhl, S. Clyens, R. Martinetti, L. Dolcini, N. Theilgaard, C.A. van Blitterswijk, Comparative in vivo study of six hydroxyapatite-based bone graft substitutes, J. Orthopaedic Res. 26 (2008) 1363-1370.

[34] H. Yuan, H. Fernandes, P. Habibovic, J. de Boer, A.M.C. Barradas, A. de Ruiter, W. R. Walsh, C.A. van Blitterswijk, J.D. de Bruijn, Osteoinductive ceramics as a synthetic alternative to autologous bone grafting, Proc. Natl. Acad. Sci. USA 107 (2010) 13614-13619.

[35] M. Bohner, L. Galea, N. Doebelin, Calcium phosphate bone graft substitutes: failures and hopes, J. Eur. Ceram. Soc. 32 (2012) 2663-2671.

[36] L. Yang, B. Harink, P. Habibovic, Calcium phosphate ceramics with inorganic additives, in: Paul Ducheyne (Ed.), Comprehensive Biomaterials, Elsevier Ltd., 2011, pp. 229-312. 
[37] P. Habibovic, J.E. Barralet, Bioinorganics and biomaterials: bone repair, Acta Biomater. 7 (2011) 3013-3026.

[38] J. Wang, K. de Groot, C. van Blitterswijkb, J. de Boer, Electrolytic deposition of lithium into calcium phosphate coatings, Dent. Mater. 25 (2009) 353-359.

[39] S. Patntirapong, P. Habibovic, P.V. Hauschka, Effects of soluble cobalt and cobalt incorporated into calcium phosphate layers on osteoclast differentiation and activation, Biomaterials 30 (2009) 548-555.

[40] S. Kulanthaivela, U. Mishra, T. Agarwal, S. Giri, K. Pal, K. Pramanik, I. Banerjee, Improving the osteogenic and angiogenic properties of synthetic hydroxyapatite by dual doping of bivalent cobalt and magnesium ion, Ceram. Int. 41 (2015) 11323-11333.

[41] L.S. Nair, C.T. Laurencin, Biodegradable polymers as biomaterials, Progressive Polym. Sci. 32 (2007) 762-798.

[42] L. Yang, S. Perez-Amodio, F.Y.F. Barrère-de Groot, V. Everts, C.A. van Blitterswijk, P. Habibovic, The effects of inorganic additives to calcium phosphate on in vitro behavior of osteoblasts and osteoclasts, Biomaterials 31 (2010) 2976-2989.

[43] C.B. Danoux, D. Barbieri, H. Yuan, J.D. de Bruijn, C.A. van Blitterswijk, P. Habibovic, In vitro and in vivo bioactivity assessment of a polylactic acid/ hydroxyapatite composite for bone regeneration, Biomatter 4 (e27664) (2014) $1-12$.

[44] B.W. Chieng, N.A. Ibrahim, W.M.Z.W. Yunus, M.Z. Hussein, Poly(lactic acid)/ poly(ethylene glycol) polymer nanocomposites: effects of graphene nanoplatelets, Polymers 6 (2014) 93-104.

[45] A. Jordá-Vilaplana, V. Fombuena, D. García-García, M.D. Samper, L. SánchezNácher, Surface modification of polylactic acid (PLA) by air atmospheric plasma treatment, Eur. Polym. J. 58 (2014) 23-33.

[46] D. Barbieri, A.J.S. Renard, J.D. de Bruijn, H. Yuan, Heterotopic bone formation by nano-apatite containing poly(D, L-lactide) composite, Eur. Cell. Mater. 19 (2010) 252-261.

[47] Y. Yuan, G. Hilliard, T. Ferguson, D.E. Millhorn, Cobalt inhibits the interaction between hypoxia-inducible factor- $\alpha$ and von Hippel-Lindau protein by direct binding to hypoxia-inducible factor- $\alpha$, J. Biol. Chem. 178 (2003) 15911-15916.
[48] K. Peters, H. Schmidt, R.E. Unger, G. Kamp, F. Prols, B.J. Berger, C.J. Kirkpatrick, Paradoxical effects of hypoxia-mimicking divalent cobalt ions in human endothelial cells in vitro, Mol. Cell. Biochem. 270 (2005) 157-166.

[49] L. Chen, A. Endler, F. Shibasaki, Hypoxia and angiogenesis: regulation of hypoxia-inducible factors via novel binding factors, Exp. Mol. Med. 41 (2009) 849-857.

[50] B.L. Krock, N. Skuli, M.C. Simon, Hypoxia-induced angiogenesis: good and evil, Genes Cancer 2 (2011) 1117-1133.

[51] Y. Liu, J.K.Y. Chan, S. Teoh, Review of vascularised bone tissue-engineering strategies with a focus on co-culture systems, J. Tissue Eng. Regen. Med. 9 (2015) 85-105.

[52] N.C. Rivron, J. Liu, J. Rouwkema, J. de Boer, C.A. van Blitterswijk, Engineering vascularised tissues in vitro, Eur. Cells Mater. 15 (2008) 27-40.

[53] Y. Liu, K. de Groot, E.B. Hunziker, BMP-2 liberated from biomimetic implant coatings induces and sustains direct ossification in an ectopic rat model, Bone 36 (2005) 745-757.

[54] A. Legrouri, J. Lenzi, M. Lenzi, Isopropanol decomposition over cobaltsubstituted calcium phosphate catalysts, Mater. Chem. Phys. 38 (1994) 94-97.

55] F. Barrère, C.M. van der Valk, R.A.J. Dalmeijer, C.A. van Blitterswijk, K. de Groot, P. Layrolle, In vitro and in vivo degradation of biomimetic octacalcium phosphate and carbonate apatite coatings on titanium implants, J. Biomed. Mater. Res. A 64 (2003) 378-387.

[56] E. Quinlan, S. Partap, M.M. Azevedo, G. Jell, M.M. Stevens, F.J. O’Brien, Hypoxiamimicking bioactive glass/collagen glycosaminoglycan composite scaffolds to enhance angiogenesis and bone repair, Biomaterials 52 (2015) 358-366.

[57] R.K. Jain, Molecular regulation of vessel maturation, Nat. Med. 9 (2003) 685693.

[58] O. Stoeltzing, M.F. McCarty, J.S. Wey, F. Fan, W. Liu, A. Belcheva, C.D. Bucana, G. L. Semenza, L.M. Ellis, Role of hypoxia-inducible factor $1 \alpha$ in gastric cancer cell growth, angiogenesis, and vessel maturation, J. Natl. Cancer Inst. 96 (2004) 946-956. 